\title{
Edutainment Tendencies among EFL Learners at the University of Halabja $\backslash$ Department of English Language
}

\author{
Omar Fouad Ghafor ${ }^{1,2}$, Goran Omar Mustafa ${ }^{1}$, Hedayat Muhamad Ahmad ${ }^{1,2}$ \\ ${ }^{1}$ Department of English Language, College of Basic Education, University of Halabja, Halabja, Kurdistan Region - F.R. Iraq \\ ${ }^{2}$ Department of English Language, College of Languages, University of Human Development, Sulaimani, Kurdistan Region, Iraq
}

\begin{abstract}
In recent years, the concept of edutainment has been introduced to the field of education. It is a blended word which has been formed from education and entertainment. The lion aim of this blending is to enhance the process of education through entertainment materials. The researchers have applied this concept to investigate students' tendencies to use various entertaining materials in their learning process at the University of Halabja\ department of English language for the academic year (2018-2019). The aim of this study is to expose the value and need of edutainment in the process of learning among these students. To achieve this goal, the researchers grounded a theoretical background about some diverged entertainment devices and their impacts on students' learning achievements. Then, formed an academic questionnaire to detect the scope of the use of entertainment sources by these students and the knock of them over their learning achievements. At the end, they analyzed and sieved the results of this questionnaire and concluded the study with their proper recommendations.
\end{abstract}

Key words-Edutainment Materials, Language Learning, Learning Achievements, New Technologies, Technological Developments.

\section{INTRODUCTION}

Edutainment is a term derived from two words; education and entertainment. It refers to the use of entertainment materials in education. There are several definitions to the term "edutainment"; The Oxford Living Dictionaries (2017) defines the term as "Video games, television programs, or other materials, intended to be both educational and enjoyable". While the American Heritage Dictionary of the English Language (1969) defines this term as "the act of learning through a medium that both educates and entertains". Moreover, Aksakal (2015, p. 1232) states that edutainment is a blended word formed from entertainment and education. The purpose of this merger is to support education with entertainment.

This gives taste and interest to the process of learning.
However, Toiskallio, 1988, cited in Walldén \& Soronen (2004), defines education as "a human activity aiming at establishing prerequisites for humans' versatile development and growth" or as "target-oriented development of personality".

On the other hand, there is no fixed definition for the term "entertainment" because it incorporates different activities by different individuals. The main purpose of entertainment in today's life is to relax people who are exhausted by modern life (Yaylaci \& Yaylaci, 2016). Bates \& Ferri (2010) clarified that "Entertainment has been a part of all cultures, from the Chauvet Cave paintings to the iPad". According to Singhal \& Rogers (2006) entertainment is becoming an important part of people's personal lives, such as shopping, traveling, eating, driving, exercising, and working experiences.

The above paragraphs clarify that the term "edutainment" is used to make a balance between "education" and "entertainment". As it is described in the definitions, education is an intellectual process and its purpose is to cultivate individuals and improve their abilities. Entertainment is fun and its purpose is to amuse individuals. Edutainment makes a mixture between these two, seemingly, different terms for the purpose of supporting education with entertainment. There are two reasons for this mixture; firstly, in today's life there are many entertainment options that we do not want to lose. Secondly, individuals are too busy and have less time to spend to both entertainment and learning process separately. So, they mix fun, entertainment, with learning, education, at the same time in order to invest more time in their learning.

The term "edutainment" was first used by "The Walt Disney Company" in 1948 to talk about the "True Life Adventure" series (Anastasia, 2015) and (Bruce, 2010). Then, it was used by Robert Heyman from the American National Geography Academic Union in 1973. He used the idea of edutainment while producing documentaries for the National Geographic Society. He produced an educational film of a game type and named it 'Education by Entertaining". Later, the term was used by Dr. Chris Daniels in 1975 to summarize the theme of his

Journal of University of Human Development

Volume 5 No. 3(2019); DOI: 10.21928/juhd.v5n3y2019.pp65-72

Regular research paper: Published 15 July 2019

Corresponding author's e-mail: omar.ghafor@uoh.edu.iq

Copyright (C2019 Omar Fouad Ghafor, Goran Omar Mustafa, Hedayat Muhamad Ahmad. This is an open access article distributed under the

Creative Commons Attribution License (CC BY-NC-ND 4.0) 
"Millennium Project", later known as "The Elysian World Project", which adopted the philosophy "Education through Entertainment". Following Dr. Daniels, the term was used by other people (Aksakal, 2015), (Bruce, 2010) and (New World Encyclopedia contributors, 2017). However, Oxford Living Dictionaries (2017) originates this term to the 1980s. The New World Encyclopedia contributors (2017) add that the term "edutainment" was used by Chris Harvey in 1983 to describe a package of computer games. In addition, Hip-hop group "Boogie Down Productions" named their fourth album "Edutainment" which was released in 1990. Moreover, the term was used as the name of a popular radio show in Knoxville TN "The Edutainment Hip Hop Show".

Furthermore, White (2003) states that a long time before Mary Poppins sang that "a spoonful of sugar helps the medicine go down", there were cultures which combined education and entertainment. People used myths to teach the rules of life and acceptable behaviors within a culture. Prophets used stories to illuminate religious beliefs. They used these stories to show the validity of moral teachings.

Learning is a psychological process, which takes place in one's mind. This means that we cannot learn complex ideas easily and quickly. So, entertainment or amusement do not have any important value if they do not serve learning. That is why edutainment does not need to be "funny" but it can be "interesting". This is, of course, good for learning (Russell, 2000) and (Brown \& Duguid, 2002). Hence, subjects mixed with entertainment are learned better.

Education and entertainment have a weird relationship. Education isn't fun and entertainment isn't serious. That is why it might seem that education and entertainment have different goals. Education aims to develop maturity, responsibility, knowledge, and growth. Good education trains us for employment, good citizenship, and deeper, more meaningful human experience. But entertainment aims to amuse and fun. However, they seem to have much in common, but they are not parallel. When education and entertainment overlap, we can enjoy the best of both: rich amusements and profound learning. The best example of this relation is entertainment materials which are, at the same time, educational. Here, we should note that entertainment is not the goal, but a way to enhance education (Ferrer, 2019). This means that edutainment materials are those materials whose format is entertainment, but their content or message is educational.

Computers and the internet have a great effect on changing traditional educational environments into the implementation of different forms of edutainment materials in the process of learning. This resulted in a complete transformation of education by developing a strong relationship between learning and entertainment. The term edutainment was used occasionally in the mid-twentieth century, but with the development of Information and communications technology (ICT) it has become more popular by students, teachers, parents, and children. Today we are witnessing a growing number of adults who are grown up with entertainment, technology and not only TV programs (Zorica, 2014, p. 4089). According to Tang, Hanneghan, \& El Rhalibi (2009), cited in
Zorica (2014, p. 4089), there is a huge gap between the way people learned in the past and the way in which new generations approach information and knowledge in the present day.

As it is described in the New World Encyclopedia contributors (2017), the pedagogy of edutainment involves the following characteristics, which show the importance of using entertainment materials in learning because they describe how learning benefits people and how it is different from one person to another:

- Relevance, which means that learning happens when people can realize the benefit of the knowledge they are given.

- Increasing learning, which means that learning is effective when people can learn at their own pace.

- Distributed learning, which means different people learn in different ways throughout different periods of time.

\section{ADVANTAGES AND DISADVANTAGES OF EDUTAINMENT}

Edusys (2019) describes the advantages and disadvantages of using edutainment materials as the following:

\section{A. Advantages}

- They encourage personalized and self-directed learning. This gives the learners more freedom and autonomy in learning.

- They help to have a better understanding of theoretical subjects. This prevents the restriction of the learners with classroom materials and helps them explore more knowledge.

- They enhance creativity and visualization. Learners know more about different subjects and things happening around them.

- They transform conventional classrooms into smart classrooms. Learners would be engaged in activities they prefer rather than spending long hours in classes.

- They support paperless learning. Learners get information from different sources, such as videos, audios, games and other entertaining materials rather than only pen and paper.

- They promote real-time learning with virtual reality. Edutainment materials create an educational environment similar to the real learning environment.

- They make learning portable and game-based. Learning would not be limited only to classroom settings. Learners can be engaged in learning activities anywhere they prefer.

- They make learning actual and experimental. Learners are actually engaged in learning activities and practice what they learn.

- They improve interactive and collaborative learning. They promote group work and learning from each other among students. 
- They encourage independent learning. Learners try to absorb things by themselves.

- They promote and improve digital culture in educational organizations. They help to bring new technologies to the educational organizations.

\section{B. disadvantages}

- There might be misleading and misguiding information.

- Computers can have a negative effect on children's growth.

- Edutainment materials can reduce social relations.

- There is a risk of misuse of technology.

- Designing and implementing edutainment materials such as computer games, television shows, videos, etc., is expensive and difficult.

\section{METHODOLOGY}

\section{A. The questionnaire}

This research study is implemented to find out the edutainment tendencies among EFL Learners at the University of Halabja \epartment of English Language. To achieve this aim, the researchers designed a questionnaire and distributed it among the students of all the stages at the Department of English Language randomly. The questionnaire is divided into three parts; the first part is devoted to collect information about the students regarding their age, sex and stage. The second and the third parts are dedicated to discover the students' perspectives towards edutainment in learning English language.

The second part includes seven questions, three of them are multiple choice questions, one of them is a yes/no question and the rest are open ended questions. The third part of the questionnaire comprises of eleven statements which should be rated by the students on a five-scale basis. The scales are (5=Strongly Agree, 4=Agree, 3=Neither Agree nor Disagree, 2=Disagree, $1=$ Strongly Disagree) .

The researchers distributed the questionnaire among the students of each stage separately to collect the sample of the study. They themselves went to the classes and illustrated the whole questionnaire for the students not to leave any room for misunderstanding of the questions. They did their best to have objective responses from the respondents. Therefore, they let the students to participate in answering the questions voluntarily and whole-heartedly. During collection of the data, some students asked the researchers questions regarding different items of the questionnaire, and the researchers illustrated the questions very clearly.

The researchers collected the completed questionnaire forms from the students and analyzed the results using Microsoft Office Excel and IBM SPSS statistics software. Later, they discussed the results and drew conclusions depending on the results they got from the questionnaire. Finally, they gave their recommendations and suggestions to the university and faculty administrators, teachers and students of University of Halabja separately to increase the use of entertainment materials inside and outside the classes and improve the way students use them to learn English language.

\section{B. Population and sample}

The population of this research study consists of the undergraduate students registered in all the four stages of department of English language at the University of Halabja for the academic year (2018-2019). The researchers selected 80 students from all the stages randomly and distributed the questionnaire among them during February 2019. They considered the following factors, as described by Dessel (2013), Smith (2013), Raosoft Inc. (2004) and the Research Advisors (2006), to determine the sample size of this study:

The population is 241 students.

The margin of error (confidence interval) is $\%-+7.6$

The confidence level is \% 90

Tables (1) and (2) show the distribution of the students according to their ages and sexes. As table (2) shows, the number of female students is more than the number of males.

TABLE (1)

DISTRIBUTION OF THE STUDENTS ACCORDING TO THEIR AGES

\begin{tabular}{|c|c|c|}
\hline Age & Frequencies & Percentages \\
\hline 18 & 13 & $16.3 \%$ \\
\hline 19 & 25 & $31.3 \%$ \\
\hline 20 & 12 & $15 \%$ \\
\hline 21 & 21 & $26.3 \%$ \\
\hline 22 & 8 & $10 \%$ \\
\hline 24 & 1 & $1.3 \%$ \\
\hline Total & 80 & $100 \%$ \\
\hline
\end{tabular}

As the table shows, the university age range of the students in the Iraqi Kurdistan Region is between 18 to 21 years. But due to delay or failure few of them are older than the age range.

TABLE (2)

DISTRIBUTION OF THE STUDENTS ACCORDING TO THEIR SEXES

\begin{tabular}{|c|c|c|c|c|}
\hline \multirow{2}{*}{ Sex } & \multicolumn{2}{|c|}{ Population } & \multicolumn{2}{c|}{ Sample } \\
\cline { 2 - 5 } & Frequencies & Percentages & Frequencies & Percentages \\
\hline Female & 171 & $71 \%$ & 64 & $80 \%$ \\
\hline Male & 70 & $29 \%$ & 16 & $20 \%$ \\
\hline Total & 241 & $100 \%$ & 80 & $100 \%$ \\
\hline
\end{tabular}

The table shows that the female students are the majority and the male students are the minority, and we see that this variation is reflected in the sample of the study. 
TABLE (3)

DISTRIBUTION OF THE STUDENTS ACCORDING TO THEIR STAGES

\begin{tabular}{|c|c|c|c|c|}
\hline \multirow{2}{*}{ Stage } & \multicolumn{2}{|c|}{ Population } & \multicolumn{2}{c|}{ Sample } \\
\cline { 2 - 5 } & Frequencies & Percentages & Frequencies & Percentages \\
\hline First & 66 & $27 \%$ & 22 & $27.5 \%$ \\
\hline Second & 77 & $32 \%$ & 26 & $32.5 \%$ \\
\hline Third & 55 & $23 \%$ & 18 & $22.5 \%$ \\
\hline Fourth & 43 & $18 \%$ & 14 & $17.5 \%$ \\
\hline Total & 241 & $100 \%$ & 80 & $100 \%$ \\
\hline
\end{tabular}

\section{Analysis and discussion of results}

Table (4) shows the frequencies and percentages of the answer choices for the first multiple choice question.

TABLE (4)

FREQUENCIES AND PERCENTAGES OF THE ANSWER CHOICES FOR QUESTION 1

From the list below, which entertainment materials do you usually use for learning? Tick all that apply.

\begin{tabular}{|c|c|c|}
\hline Entertainment Materials & Frequencies & Percentages \\
\hline Computer\Mobile Apps & 1 & $1.3 \%$ \\
\hline Movies & 2 & $2.5 \%$ \\
\hline Movies and ComputerlMobile Apps & 7 & $8.8 \%$ \\
\hline Movies and Language Games & 1 & $1.3 \%$ \\
\hline Movies, Language Games and tv Shows & 1 & $1.3 \%$ \\
\hline Movies and Songs & 9 & $11.3 \%$ \\
\hline $\begin{array}{l}\text { Movies, Songs and ComputerlMobile } \\
\text { Apps }\end{array}$ & 12 & $15 \%$ \\
\hline Movies, Songs and Language Games & 4 & $5 \%$ \\
\hline $\begin{array}{l}\text { Movies, Songs, Language Games and } \\
\text { ComputerlMobile Apps }\end{array}$ & 1 & $1.3 \%$ \\
\hline $\begin{array}{l}\text { Movies, Songs, Language Games and Tv } \\
\text { Shows }\end{array}$ & 1 & $1.3 \%$ \\
\hline $\begin{array}{l}\text { Movies, Songs, Language Games, Tv } \\
\text { Shows and ComputerlMobile Apps }\end{array}$ & 6 & $7.5 \%$ \\
\hline Movies, Songs and Tv Shows & 7 & $8.8 \%$ \\
\hline $\begin{array}{l}\text { Movies, Songs, Tv Shows and } \\
\text { ComputerlMobile Apps }\end{array}$ & 10 & $12.5 \%$ \\
\hline Movies and Tv Shows & 4 & $5 \%$ \\
\hline $\begin{array}{l}\text { Movies, Tv Shows and ComputerlMobile } \\
\text { Apps }\end{array}$ & 4 & $5 \%$ \\
\hline Songs & 2 & $2.5 \%$ \\
\hline Songs and ComputerlMobile Apps & 4 & $5 \%$ \\
\hline $\begin{array}{l}\text { Songs, Language Games, Tv Shows and } \\
\text { ComputerlMobile Apps }\end{array}$ & 1 & $1.3 \%$ \\
\hline Songs and Tv shows & 1 & $1.3 \%$ \\
\hline $\begin{array}{l}\text { Songs, Tv Shows and ComputerlMobile } \\
\text { Apps }\end{array}$ & 1 & $1.3 \%$ \\
\hline Tv Shows and ComputerlMobile Apps & 1 & $1.3 \%$ \\
\hline Total & 80 & $100 \%$ \\
\hline
\end{tabular}

As the table indicates, some of the students only use one entertainment material to learn English language; $1.3 \%$ of the students usually use Computerlmobile applications, $2.5 \%$ use movies, and $2.5 \%$ of them use songs. Some students usually use two different entertainment materials in learning English language; $8.8 \%$ of them use movies and Computerlmobile applications, $1.3 \%$ use movies and language games, $11.3 \%$ use movies and songs, $5 \%$ use movies and TV shows, 5\% use songs and computer Imobile applications and $1.3 \%$ use songs and TV shows in their language learning. Some other learners use three different entertainment materials for their learning; Only $1.3 \%$ of the students use movies, language games and TV shows, but $15 \%$ of the students use movies, songs and computerlmobile applications for learning which is the highest percentage of using entertainment materials. Moreover, $5 \%$ of the students use movies, songs and language games, $8.8 \%$ of them use movies, songs and TV shows and 5\% of them use movies, TV shows and computer $\backslash$ mobile applications in learning English language. Some other learners use four different entertainment materials in their learning process; $1.3 \%$ of them use movies, songs, language games and computerlmobile applications, $1.3 \%$ of them use movies, songs, language games and TV shows. But when it comes to use movies, songs, TV shows and computerlmobile applications together for learning, the percentage would rise by $12 \%$. Then, $1.3 \%$ of them use songs, language games, TV shows and computer $\backslash$ mobile application. Only $7.5 \%$ of the students use all the given entertainment materials in the questionnaire for their learning; movies, songs, language games, TV shows and computer \mobile application.

When we study these data thoroughly we see that:

1. Entertainment materials are considered as a significant part of education and learning English language. We can say that they are inseparable part of the students' learning process as $0 \%$ of them go for the last option in the questionnaire, never use entertainment materials for learning.

2. Most of the students use more than one entertainment material for learning English language.

3. Movies are the most common entertainment material among the students for learning, their frequency is $86.6 \%$.

4. The second common entertainment material for learning among students is songs as the percentage is $72.5 \%$.

5. Computerlmobile applications become the third common entertainment material among the learners. They are used by $57.7 \%$.

6. $\quad 62.7 \%$ of the learners use movies and songs together for learning English language. They are the most widely used two items together by the learners.

Table (5) indicates the frequencies and percentages for the second and third questions. 
TABLE (5)

FREQUENCIES AND PERCENTAGES OF THE ANSWER CHOICES FOR THE QUESTIONS $(2,3)$

\begin{tabular}{|l|l|c|c|}
\cline { 3 - 4 } \multicolumn{2}{c|}{} & Q2 & Q3 \\
\hline \multirow{2}{*}{ Less than an hour } & Frequencies & 10 & 24 \\
\cline { 2 - 4 } $1-2$ hours & Percentages & $12.5 \%$ & $30 \%$ \\
\hline \multirow{2}{*}{$2-4$ hours } & Frequencies & 28 & 36 \\
\cline { 2 - 4 } & Percentages & $35 \%$ & $45 \%$ \\
\hline \multirow{2}{*}{$4-5$ hours } & Frequencies & 25 & 17 \\
\cline { 2 - 4 } & Percentages & $31.3 \%$ & $21.3 \%$ \\
\hline \multirow{2}{*}{ More than 5 hours } & Frequencies & 7 & 3 \\
\cline { 2 - 4 } & Percentages & $8.8 \%$ & $3.8 \%$ \\
\cline { 2 - 4 } & Frequencies & 10 & 0 \\
\hline \multirow{2}{*}{ Never } & Percentages & $12.5 \%$ & $0 \%$ \\
\cline { 2 - 4 } & Frequencies & 0 & 0 \\
\cline { 2 - 4 } & Percentages & $0 \%$ & $0 \%$ \\
\hline
\end{tabular}

As we see from the table, in the answer of the second question "How much time do you generally spend in using entertainment materials daily?" and third question "How much time do you spend daily in using entertainment materials for learning?" $12.5 \%$ of the learners stated that they spend less than an hour of their daily time in using entertainment materials for no educational purpose. But when it comes to spend the same amount of time in using entertainment materials for learning, the percentage rises by $30 \% .35 \%$ of the learners spend only one to two hours daily in using entertainment materials generally for no educational use, but $45 \%$ of them spend one to two hours of their time every day in using entertainment materials for learning. $31.3 \%$ of the students spend two to four hours daily in using entertainment materials generally but when it comes to spending the same amount of time daily in using entertainment materials for learning the percentage falls by $21.3 \%$. $8.8 \%$ of the respondents spend four to five hours daily in using entertainment materials generally. Again, when it comes to spend the same amount of time daily in using entertainment materials for learning the percentage falls to $3.8 \%$. $12.5 \%$ of the respondents spend more than five hours daily in using entertainment materials generally, but there are no students who spend more than five hours in using entertainment materials for learning.

The above responses tell us a lot about the learners and how they spend their time daily. We can summarize them in the following points:

1. Every student uses an amount of time in using entertainment materials, whether it is for general use or for learning.

2. The learners spend more time in using entertainment materials generally, for personal use, rather than for learning.

3. Only in two options (less than an hour and one to two hours) the students wrote that they spend more time in using entertainment materials for learning.

4. In the other options; two to four hours, four to five hours and more than five hours, the learners stated that they spend more time in using entertainment materials for no educational purpose.
5. There are no students who never spend their time in using entertainment materials for learning and for general use as well.

Table (6) shows the frequencies and percentages for the fourth question. As we see from the table, $55 \%$ of the students stated that they used entertainment materials for learning before attending university, $31.3 \%$ of them stated that they did not use such materials and $13.8 \%$ of them are not sure.

TABLE (6)

FREQUENCIES AND PERCENTAGES OF THE ANSWER CHOICES FOR QUESTION (4)

Have you used entertainment materials for learning before attending university?

\begin{tabular}{|l|c|c|}
\hline \multicolumn{1}{|c|}{ Answers } & Frequencies & Percentages \\
\hline I am not sure & 11 & $13.8 \%$ \\
\hline NO & 25 & $31.3 \%$ \\
\hline Yes & 44 & $55 \%$ \\
\hline Total & 80 & $100 \%$ \\
\hline
\end{tabular}

The students who answered the fourth question with "yes" were asked to write the names of the entertainment materials that they used before attending university and they stated the following: movies, songs, TV shows, smart phones, reading books, language games, and computers.

The answers show that students used different entertainment materials for learning language in different ways. Moreover, the students who answered this question with "yes" stated the following:

1. They can develop their command of language through using different entertainment materials.

2. They know how to use some entertainment materials for learning language.

Table (7) shows the frequencies and percentages for the fifth question.

TABLE (7)

FREQUENCIES AND PERCENTAGES OF THE ANSWER CHOICES FOR QUESTION (5)

\begin{tabular}{|c|c|c|}
\hline \multicolumn{3}{|c|}{ How do you prefer to learn English language and why? } \\
\hline Answers & Frequencies & Percentages \\
\hline $\begin{array}{c}\text { Without entertainment } \\
\text { materials }\end{array}$ & 5 & $6.3 \%$ \\
\hline $\begin{array}{c}\text { With entertainment } \\
\text { materials }\end{array}$ & 75 & $93.8 \%$ \\
\hline Total & 80 & $100 \%$ \\
\hline
\end{tabular}

Concerning the reasons for their preferences, students provided the following reasons:

Students who prefer to learn English language with entertainment materials:

1. They feel confident in using entertainment materials in their language learning process such as improving pronunciation and making expressions. Moreover, they can use them easily.

2. They believe that using entertainment materials helps them have more achievements in their language learning 
process. In addition, they make a better learning environment for them.

3. They think that using entertainment materials saves them time to learn.

Students who prefer to learn English language without entertainment materials:

1. Using entertainment materials may waste their times.

2. They used to learn without entertainment materials and keeping books instead.

3. Entertainment materials are not always available. This pushes them not to use them much.

4. Using entertainment materials may damage their health.

In the answer of the sixth question, "In your opinion, what are the major advantages of using entertainment materials for learning?", the students mentioned the following advantages:

1. They help the students to learn quickly and easily.

2. They help the students to save time.

3. They help the students to experience an effective way of learning.

4. They make the students to enjoy themselves while they learn.

5. They help the students to improve their language skills.

6. They drive the students to be positive in learning.

7. They help the students to improve their pronunciation.

8. They help the students to make a good environment for learning.

9. They help the students to have different options in learning.

10. They help the students to know about others' cultures.

11. They help the students to learn independently.

TABLE (8)

PERCENTAGES AND AVERAGES OF THE RATING SCALES FOR THE STATEMENTS (8-18)

\begin{tabular}{|c|c|c|c|c|c|c|c|}
\hline \multirow{2}{*}{ Zu } & \multirow{2}{*}{ Statements } & \multicolumn{5}{|c|}{ Scales } & \multirow{2}{*}{ 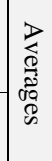 } \\
\hline & & 1 & 2 & 3 & 4 & 5 & \\
\hline 8 & $\begin{array}{l}\text { I am interested in } \\
\text { using entertainment } \\
\text { materials generally. }\end{array}$ & $0 \%$ & $3.8 \%$ & $11.3 \%$ & $58.8 \%$ & $26.3 \%$ & 4.1 \\
\hline 9 & \begin{tabular}{|l} 
I am interested in \\
using entertainment \\
materials for learning \\
English language.
\end{tabular} & $1.3 \%$ & $0 \%$ & $7.5 \%$ & $50 \%$ & $41.3 \%$ & 4.3 \\
\hline 10 & $\begin{array}{l}\text { Using entertainment } \\
\text { materials motivates me } \\
\text { in my English } \\
\text { language learning } \\
\text { process }\end{array}$ & $0 \%$ & $5 \%$ & $10 \%$ & $47.5 \%$ & $37.5 \%$ & 4.2 \\
\hline 11 & $\begin{array}{l}\text { Using entertainment } \\
\text { materials helps me } \\
\text { have more } \\
\text { achievements in my } \\
\text { English language } \\
\text { learning process. }\end{array}$ & $2.5 \%$ & $3.8 \%$ & $13.8 \%$ & $43.8 \%$ & $36.3 \%$ & 4.1 \\
\hline
\end{tabular}

\begin{tabular}{|l|l|l|l|l|l|l|l|}
\hline 12 & $\begin{array}{l}\text { To me, it is easy to use } \\
\text { entertainment } \\
\text { materials for learning } \\
\text { English language. }\end{array}$ & $2.5 \%$ & $6.3 \%$ & $20 \%$ & $53.8 \%$ & $17.5 \%$ & 3.8 \\
\hline $\begin{array}{l}\text { Using entertainment } \\
\text { materials minimizes } \\
\text { the time I need in my } \\
\text { English language } \\
\text { learning process. }\end{array}$ & $2.5 \%$ & $5 \%$ & $33.8 \%$ & $42.5 \%$ & $16.3 \%$ & 3.7 \\
\hline 14 & $\begin{array}{l}\text { Entertainment } \\
\text { materials create a } \\
\text { better learning } \\
\text { environment to me. }\end{array}$ & $1.3 \%$ & $3.8 \%$ & $26.3 \%$ & $52.5 \%$ & $16.3 \%$ & 3.8 \\
\hline 15 & $\begin{array}{l}\text { Entertainment } \\
\text { materials make my } \\
\text { language learning fun. }\end{array}$ & $1.3 \%$ & $6.3 \%$ & $17.5 \%$ & $42.5 \%$ & $32.5 \%$ & 4.0 \\
\hline 16 & $\begin{array}{l}\text { My teachers use } \\
\text { lntertainment } \\
\text { materials inside the } \\
\text { class. }\end{array}$ & $8.8 \%$ & $18.8 \%$ & $27.5 \%$ & $37.5 \%$ & $7.5 \%$ & 3.2 \\
\hline $\begin{array}{l}\text { Using entertainment } \\
\text { materials by my } \\
\text { teachers inside the } \\
\text { class has a positive } \\
\text { impact on my English } \\
\text { language learning } \\
\text { process. }\end{array}$ & $1.3 \%$ & $5 \%$ & $20 \%$ & $52.5 \%$ & $21.3 \%$ & 3.9 \\
\hline $\begin{array}{l}\text { My classes are } \\
\text { equipped with } \\
\text { essential tools for } \\
\text { using entertainment } \\
\text { materials for English } \\
\text { language learning. }\end{array}$ & $7.5 \%$ & $27.5 \%$ & $40 \%$ & $18.8 \%$ & $6.3 \%$ & 2.9 \\
\hline $\begin{array}{l}\text { Average } \\
\text { nase }\end{array}$ & $2.6 \%$ & $7.8 \%$ & $20.7 \%$ & $45.5 \%$ & $23.6 \%$ & 3.8 \\
\hline
\end{tabular}

In the answer of the seventh question, "in your opinion, what are the major disadvantages of using entertainment materials for learning?" the students listed the following disadvantages:

1. Using entertainment materials wastes too much time of them.

2. Using entertainment materials makes them to face social and health problems.

3. Using entertainment materials makes them to avoid reading books.

4. Using entertainment materials makes them to face lack of writing.

5. Using entertainment materials loses their money.

6. Using entertainment materials makes them to be addicted to such materials.

If we compare the answers of these two questions with section II of the theoretical part of this paper, we can see that most of the advantages and disadvantages stated by the students are similar to the ones described in the theoretical part.

In the third part of the questionnaire, the students were asked to reflect on using entertainment materials in their learning process by rating eleven statements on a five-scale basis. The rating scales are as follows:

$1=$ Strongly Disagree

$2=$ Disagree

$3=$ Neither Agree nor Disagree

$4=$ Agree

5 = Strongly Agree 
Table (8) shows the percentages and averages of the rating scales for each statement.

We can read the following facts from the table:

1. Most of the respondents are interested in using entertainment materials generally. Moreover, they are interested in using entertainment materials for learning as well.

2. Most of the learners believe that using entertainment materials motivates them in their English language learning process and also to have more achievements in their English language learning process.

3. Most of the students think that it is easy to use entertainment materials for learning English language. At the same time, using entertainment materials minimizes the time they need in learning English language.

4. Most of the participants believe that entertainment materials create a better learning environment to them and make their language learning fun.

5. Some of the students think that their teachers use entertainment materials inside the class, but most of them said that using entertainment materials by their teachers inside the class has a positive impact on their English language learning process.

6. Most of the respondents believe that their classes are not equipped with essential tools for using entertainment materials for English language learning.

\section{CONCLUSIONS}

On the basis of the questionnaire results, the researchers reached the following conclusions:

1. Nowadays edutainment materials are considered as a significant part of education and an inseparable part of the English language learning process. They are widely used among students to learn English language.

2. The students are interested in using entertainment materials generally. Also, they use them to learn English language.

3. There are no students who do not use any type of entertainment materials either for general use or learning.

4. Movies and songs are the most widely used materials among the entertainment materials to learn English language.

5. Learners devote a lot of time to use entertainment materials generally but when it comes to learning English language, they devote less time.

6. Using entertainment materials motivates the students to learn English language.

7. Using entertainment materials helps the students to learn English language easier.

8. Most of the learners find it easy to use entertainment materials whether for general purpose or for learning English language.

9. Using entertainment materials minimizes the time learners need to learn English language.Using entertainment materials provides a better educational and learning environment for the students and they make the process of learning fun.

10. Some teachers use entertainment materials inside the classes, but it is still not within students' expectations.

11. Using entertainment materials inside the classes by the teachers leaves a positive effect on the learners and their learning process.

12. Classes are not totally equipped with essential tools for using entertainment materials for English language learning.

\section{RECOMMENDATIONS}

Based on the conclusions reached, the researchers have the following recommendations for the university administrators, teachers and students:

1. College and department administrators need to equip the classes, at least some of them, with essential tools for using entertainment materials to learn English language as they are a significant part of the education process.

2. Teachers have to use more entertainment materials in their classes as much as possible because the process of learning would be much easier and fun with such materials.

3. The department administrators need to devote at least two hours per week for students to watch movies and discuss them together.

4. Students have to increase the amount of time they spend in using entertainment materials for learning English language and decrease the time they spend in using entertainment materials just for pleasure.

5. Students need to establish movie clubs and watch one or two movies per week to have a better educational and learning environment.

6. Teachers should guide learners, as much as possible, to use entertainment materials in their learning process in the best way.

\section{RFERENCES}

Addis, M. (2002). New technologies and cultural consumption - edutainment is born! European Journal of Marketing, 729-736.

Aksakal, N. (2015). Theoretical View to The Approach of The Edutainment. Procedia - Social and Behavioral Sciences (pp. 1232-1239). Prague: Elsevier Ltd.

Anastasia. (2015, March 20). Cleverism: Edutainment. Retrieved from Cleverism: https://www.cleverism.com/lexicon/edutainment/

Anikina, O. V., \& Yakimenko, E. V. (2015). Edutainment as a modern technology of education. International conference on research paradigms transformation in social sciences 2014. Procedia-social and behavioral sciences (pp. 475-479). Tomsk: Elsevier Ltd.

Bates, S., \& Ferri, A. (2010). What's entertainment? Notes toward a definition. Studies in Popular Culture, 1-20.

Brown, J. S., \& Duguid, P. (2002). The Social Life of Information. Boston: Harvard Business School Press. 
Bruce, E. (2010, September 1). Edutainment. Retrieved from Historically Speaking; Making sense of it all: https://idiomation.wordpress.com/tag/robert-heyman/

Colace, F., De Santo, M., Pietrosanto, A., \& Troiano, A. (2006). Work in Progress: Bayesian Networks for Edutainment. 36th ASEE/IEEE Frontiers in Education Conference (pp. 13-14). San Diego: IEEE.

Dessel, G. V. (2013, February 13). CheckMarket. Retrieved from CheckMarket Web site: https://www.checkmarket.com/2013/02/howto-estimate-your-population-and-survey-sample-size/

Edusys. (2019, March 08). Retrieved from Edusys.co website: https://www.edusys.co/blog/what-is-edutainment

Ferrer, D. (2019, February 1). Magazine: The best schools. Retrieved from The QUAD: https://thebestschools.org/magazine/edutainmentgamify-education/

Jarvin, L. (2015). Edutainment, games, and the future of education in a digital world. The global context for new directions for child and adolescent development, 33-40.

Korkmaz, Ş. Ç. (2013). Language games as a part of edutainment. 3rd World Conference on Learning, Teaching and Educational Leadership. Procedia - Social and Behavioral Sciences, 1249-1253.

Molnar, A. R., \& Deringer, D. K. (1984). Edutainment: How to learn to laugh and learn. IEEE Spectrum, 114-118.

New World Encyclopedia contributors. (2017, September 23). Edutainment. Retrieved from New World Encyclopedia: http://www.newworldencyclopedia.org/p/index.php?title=Edutainme nt\&oldid $=1006900$

Noddings, N. (2003). Happiness and Education. Cambridge: Cambridge University Press.

Okan, Z. (2003). Edutainment: Is learning at risk? British journal of educational technology, 255-264.

Oxford Living Dictionaries. (2017). Retrieved from Oxford dictionaries: https://en.oxforddictionaries.com/definition/edutainment

Raosoft Inc. (2004). Retrieved from Raosoft web site: http://www.raosoft.com/samplesize.html

Rapeepisam, K., Wong, K. W., Fung, C. C., \& Depickere, A. (2006). Similarities and differences between "learn through play" and "edutainment". Proceedings of the 3rd Australian Conference on Interactive Entertainment, 28-32.

Russell, G. (2000). School education in the age of the ubiquitous networked computer. Technology in Society (Tech Soc), 389-400.

Singhal, A., \& Rogers, E. M. (2006). A theoretical agenda for entertainmentEducation. Communication theory, 117-135.

Smith, S. M. (2013, April 08). Qualtrics. Retrieved from Qualtrics Web site: https://www.qualtrics.com/blog/determining-sample-size/

Tang, S., Hanneghan, M., \& El Rhalibi, A. (2009). Games-Based Learning Advancements for Multi-Sensory Human Computer Interfaces: Techniques and Effective Practices. New York: IGI Global.

The American Heritage Dictionary of the English Language. (1969). Boston: Houghton Mifflin Harcourt Publishing Company.

The Research Advisors. (2006). Retrieved from The Research Advisors Web site: http://www.research-advisors.com/tools/SampleSize.htm

Thompson, P. M. (2007). The influence of popular culture and entertainment media on adult education. New directions for adult and continuing education, 83-90.

Walldén, S., \& Soronen, A. (2004). Edutainment from television and computers to cigital television. Tampere: University of Tampere Hypermedia Laboratory.
White, R. (2003). That's Edutainment. Retrieved from White Hutchinson Leisure \& Learning Group: https://www.whitehutchinson.com/leisure/articles/edutainment.shtml

Yaylaci, F. G., \& Yaylaci, A. F. (2016). Understandings and tendencies of edutainment in Turkey: An evaluation based on Neil Postman's criticism on education, entertainment and technology. contemporary educational technology, 241-263.

Zin, H. M., \& Zain, N. Z. (2010). The effects of edutainment towards students' achievements. Regional Conference on Knowledge Integration in ICT (pp. 64-72). Putrajaya: Kolej Universiti Islam Antarabangsa Selangor.

Zorica, M. B. (2014). Edutainment at the higher education as an element for the learning success. Proceedings of EDULEARN14 Conference (pp. 4089-4097). Barcelona: IATED. 